\title{
Pregnancy and childbirth in women aged 40 and over at befelatanana maternity, Madagascar
}

\author{
Rakotomalala Nivoarimelina Zoly ${ }^{1,2 *}$, Rakotozanany Besaina ${ }^{3,4}$, \\ Razafindraibe Andriatompoina Felanarivo ${ }^{3,4}$, Ramarokoto \\ Malalafinaritra Patrick Marco ${ }^{1,2}$, Rafamatanantsoa Jean Florent ${ }^{3,4}$, \\ Kapche Wato Edith ${ }^{3,4}$ and Randriambololona Domoina Malala \\ Aurélia ${ }^{5,6}$ \\ ${ }^{1}$ Mother-Child Complex, Androva Hospital, Mahajanga, Madagascar \\ ${ }^{2}$ Faculty of Medecine, Mahajanga, Madagascar \\ ${ }^{3}$ Befelatanana Maternity, Antananarivo, Madagascar \\ ${ }^{4}$ Faculty of Medicine, Antananarivo, Madagascar \\ ${ }^{5}$ Place Kabary Hospital, Diego, Madagascar \\ ${ }^{6}$ Faculty of Medicine, Diego, Madagascar
}

\section{Abstract}

Objective: Pregnancy after age 40 remains a concern as it exposes to particular obstetrical complications. Our study aims to determine the risks of complications related to pregnancy and childbirth of women aged 40 and over.

Study design: We carried out a cross-sectional analytical study of a historical cohort comparing the progress and the outcome of pregnancy in women 40 years of age and over to those aged 20 and 35 who gave birth at the University Hospital of Obstetrics and Gynecology in Befelatanana, from $1^{\text {st }}$ January 2010 to 31 December 2013.

Results: The prevalence of childbirth among 40 years old and over was $0.61 \%$. They were multiparous and large multiparous in $88 \%$ of the cases. The analysis showed that parturients aged 40 years and older were at significant risk for caesarean section, with three times the risk of emergency caesarean section. The frequency of this emergency caesarean section increased with parity $\left(R R=3.04\right.$ [2.15-4.30], $\left.p=10^{-10}\right)$. Among their neonates, $23.42 \%$ were hypotrophic, $22.86 \%$ premature, $12 \%$ asphyxiated at birth, $13.14 \%$ admitted to neonatal resuscitation and $5.71 \%$ died in utero, but without significant difference with the group unexposed. Perinatal death was $7.43 \%$ in women aged 40 and over vs. $4 \%$ in 20 to 35 year olds $(R R=1.85[0,89-3,86] ; p=0.052)$.

Conclusion: We found that pregnancies after 40 years were not exposed to pregnancy-related pathologies or specific fetal complications. The use of an emergency cesarean is, however, frequent.

\section{More Information}

*Address for Correspondence: Rakotomalala Nivoarimelina Zoly, Complexe Mère-Enfant, Androva Hospital, Mahajanga, Madagascar, Tel: (261) 3473760 13; Email: rajol42@yahoo.fr

Submitted: 09 December 2019

Approved: 23 December 2019

Published: 24 December 2019

How to cite this article: Zoly RN, Besaina R, Felanarivo RA, Marco RMP, Florent RJ, et al. Pregnancy and childbirth in women aged 40 and over at befelatanana maternity, Madagascar. Arch Pathol Clin Res. 2019; 3: 022-027.

DOI: dx.doi.org/10.29328/journal.apcr.1001015

Copyright: (c) 2019 Zoly RN, et al. This is an open access article distributed under the Creative Commons Attribution License, which permits unrestricted use, distribution, and reproduction in any medium, provided the original work is properly cited.

Keywords: Childbirth; 40 ages; Cesarean section; Complications; Pregnancy

W) Check for updates

(๑) OPEN ACCESS

\section{Introduction}

Women aged 35 and over were considered older pregnant women. With the decline in the age of motherhood in the world, the concept of older parturients is for women aged 40 [1]. Despite the decreased fertility at the age of 35, the number of pregnancies occurring after age 40 increases; several factors of "society" are incriminated: the easy access to contraception, the higher education, the professional activities, late marriages, second unions and the possibility of assisted procreation; "The social benefit could lead to biological disadvantage" [2].
In Africa and Madagascar where fertility remains high at around 5.2 children per woman, women continue to procreate even after their forties [3] despite the increased risk of maternal and perinatal morbidities and deaths. In these women aged 40 years and older, requiring heavy care or with sequelae [1]. The first pregnancy in older women is also considered high risk $[4,5]$.

Despite the remarkable decline in maternal mortality in the industrialized countries, it remains high in developing countries, particularly in Madagascar, where the maternal mortality rate is estimated at 498 per 100,000 births 
and neonatal mortality of 24 per 1,000 newborns [3]. Reproductive behavior constitutes a significant risk of mortality in a country where fertility remains high [6].

To assess the risks associated with late pregnancy among Malagasy women, we conducted a study among parturients who attend a reference hospital in the capital of Madagascar. Our main objective was to determine the risks associated with pregnancy and childbirth for women aged 40 and over. As secondary objectives, we wanted to determine the prevalence of childbirth among women aged 40 and over and describe their socio-demographic and obstetric characteristics.

\section{Materials and Methods}

\section{Study design and period}

It was a retrospective and analytical study, historical cohort type, performed at the University Hospital of Obstetric Gynecology Befelatanana (CHU-GOB) or Befelatanana maternity, for a period of 4 years, from January 1, 2010 to December 31, 2013.

\section{Study framework}

The CHU-GOB is a level 3 reference maternity hospital in the capital of Madagascar, which carries out an average of 8,000 deliveries a year.

\section{Population d'étude}

Our study population included parturients admitted for delivery during the study period.

Inclusion criteria: Included as "exposed" were mothers aged 40 and over who gave birth in this maternity unit with a gestational age $\geq 22$ weeks of amenorrhea (WA) and as "unexposed" parturients aged 20 to 35 who gave birth in the same establishment with a term $\geq 22$ WA. We had two unexposed parturients for each exposed parturient and both exposed and unexposed groups were matched by gestational age at delivery.

Exclusion criteria: Parturients with incomplete records were excluded while parturients aged under 20 and those between 35 and 40 were not included.

\section{Parameters studied}

Maternal parameters were: maternal age, parity, gestational age, number of prenatal consultations, antecedents, pathologies during pregnancy, delivery patterns, caesarean section indications, and postpartum complications. The fetal parameters studied were: the weight of the newborn, the Apgar index at the $5^{\text {th }}$ minute, the possible admission to neonatal resuscitation and the neonatal outcome.

\section{Theory and calculation}

Statistical analysis was performed by the Epi Info
Software version 7.1.3. The Chi2 test was used for the comparison of proportions. Relative Risk $(R R)$ was affected by a $95 \%$ confidence interval $(C I)$ to compare the risks of complications of pregnancy and delivery in exposed and unexposed women, both groups being matched according to their parity. The difference was statistically significant with $p<0.05$.

\section{Results}

\section{Descriptive result}

During the study period, we selected 175 cases of pregnant women aged 40 and over among 30488 parturients with a prevalence of $0.57 \%$. This frequency was $0.29 \%$ in 2010 then $0.08 \%$ in 2011 and 2012 and $0.12 \%$ in 2013 . Table 1 summarizes the socio-demographic and obstetrical characteristics of parturients. The mean age of the exposed group was $41.51 \pm 0.56$ years with an extreme age of 49 years, while that of the unexposed group was $26.82 \pm 3.38$ years. Just under half were housewives in both groups. Twelve percent of women aged 40 and over were primiparous and $53.71 \%$ were multiparous. A previous hypertension was found in $5.71 \%$ of cases in the 40 years and over, vs. $2.28 \%$ in the unexposed group. There were at least four prenatal consultations in both groups in over $60 \%$ of cases. Delivery occurred in more than $70 \%$ of cases in both groups. The average weight of newborns for women aged 40 and over was $2,825 \mathrm{~g} v s .2,895 \mathrm{~g}$ for women aged 20 to 35 .

\section{Analytical result}

Delivery modality: Parturients aged 40 and over delivered by caesarean section in $46.28 \%$ of cases vs. $33.71 \%$ in parturients aged 20 to 35 ( $p=0.0027, R R=1.41,95 \% C I$ = 1.12). at 1.77). Table 2 shows the relationship between obstetric prognosis and maternal age as well as parity; Table 3 shows the maternal complications' risk as a function of age. The risk of emergency cesarean section was increased threefold in older women compared to young women (36.57\% vs. $12 \%, p=10^{-10}, R R=3.04,95 \% C I=2.15$ to 4,30 ). After pairing according to parity, this fact was especially noted in multiparas $(19.43 \%$ vs. $0.57 \%, p=0.0002)$. In primiparous women, younger women were more urgently cesarized compared with older women $(p=0.0005)$. The proportion of emergency caesareans was increasing with parity among women aged 40 and over. In case of vaginal delivery, the use of episiotomy was significantly lower in older primiparous women compared to young primiparous $(2.28 \% v$ v. $11.42 \%$, $p=0.0452$ ). There was no difference in the two groups about risk of instrumental extraction.

Maternal complications: Maternal age 40 years and older was not at risk of hypertensive disorders $(p=0.236)$, placenta previa ( $p=0.136)$ or gestational diabetes $(p=0.538)$ compared to age between 20 and 35 years. Postpartum 
Table 1: General profile of parturients and fetuses by maternal age.

\begin{tabular}{|c|c|c|c|c|c|}
\hline Parameters & \multicolumn{2}{|c|}{ Parameters detail } & $\begin{array}{c}\text { Women } \geq 40 \text { years old } \\
(n=175) \\
n(\%)\end{array}$ & $\begin{array}{l}\text { Women } 20 \text { to } 35 \text { years old } \\
\qquad \begin{array}{c}(n=350) \\
n(\%)\end{array}\end{array}$ & $p$ value \\
\hline \multirow{5}{*}{ Profession } & \multicolumn{2}{|c|}{ Housewife } & $80(45,71)$ & $153(43,72)$ & 0,3867 \\
\hline & \multicolumn{2}{|c|}{ Civil servant } & $31(17,71)$ & $55(15,71)$ & 1 \\
\hline & \multicolumn{2}{|c|}{ Tradeswomen } & $26(14,86)$ & $52(14,86)$ & 0,3599 \\
\hline & \multicolumn{2}{|c|}{ Farmer } & $14(8,00)$ & $11(3,14)$ & 0,0414 \\
\hline & \multicolumn{2}{|c|}{ Other* } & $24(3,72)$ & $79(22,57)$ & 0,0290 \\
\hline \multirow{3}{*}{ Previous deliveries } & \multicolumn{2}{|c|}{1} & $21(12,00)$ & $157(44,85)$ & 0,00003 \\
\hline & \multicolumn{2}{|c|}{$2-3$} & $60(34,29)$ & $154(44)$ & 1 \\
\hline & \multicolumn{2}{|c|}{$\geq 4$} & $94(53,71)$ & $39(11,14)$ & 0,000000000 \\
\hline \multirow{3}{*}{ Number of prenatal consultations } & \multicolumn{2}{|c|}{$\geq 4$} & $82(67,21)$ & $161(71,88)$ & 1 \\
\hline & \multicolumn{2}{|c|}{$<4$} & $40(32,79)$ & $63(28,12)$ & 0,1840 \\
\hline & \multicolumn{2}{|c|}{ Aucune } & $53(32,12)$ & $126(38,18)$ & 0,1854 \\
\hline \multirow{5}{*}{ Gestational age at the time of delivery (weeks) } & \multicolumn{2}{|c|}{ [22-28] } & $2(1,14)$ & $5(1,43)$ & 0,3128 \\
\hline & \multicolumn{2}{|c|}{ [28-34] } & $16(9,14)$ & $23(6,57)$ & 0,3043 \\
\hline & \multicolumn{2}{|c|}{ [34-37] } & $22(12,58)$ & $41(11,71)$ & 0,0651 \\
\hline & \multicolumn{2}{|c|}{ [37-41] } & $121(69,14)$ & $245(70,00)$ & 1 \\
\hline & \multicolumn{2}{|c|}{$\geq 41$} & $14(8,00)$ & $36(10,29)$ & 0,0107 \\
\hline \multirow{4}{*}{ Maternal medical history } & \multicolumn{2}{|c|}{ Diabetes } & $1(0,57)$ & 0 & 0,3241 \\
\hline & \multicolumn{2}{|c|}{ Hypertension } & $10(5,71)$ & $8(2,28)$ & 0,0253 \\
\hline & \multicolumn{2}{|c|}{ Asthma } & $1(0,57)$ & 0 & 0,3241 \\
\hline & \multicolumn{2}{|c|}{ None } & $163(93,14)$ & $342(97,71)$ & 1 \\
\hline \multirow{3}{*}{ Pregnancy pathologies } & Hypertensi & sorders & $10(5,71)$ & $15(4,28)$ & 0,236 \\
\hline & Gestationa & abetes & $1(0,57)$ & $1(0,28)$ & 0,538 \\
\hline & Placent & evia & $9(5,14)$ & $11(3,14)$ & 0,137 \\
\hline & Vaginal & very & $94(53,71)$ & $232(66,28)$ & 0,055 \\
\hline Delivery route & & Emergency & $64(36,57)$ & $42(12,00)$ & $10^{-10}$ \\
\hline Demvery route & Caesarean section & Scheduled & $17(09,71)$ & $76(21,71)$ & \\
\hline & & Total & $81(46,28)$ & $118(33,71)$ & 0,0027 \\
\hline Angar index in the $5^{\text {th }}$ minute & $<$ & & $16(9,14)$ & $25(7,14)$ & 0,2121 \\
\hline Apgar minex mi the s mintuce & $\geq$ & & $159(90,86)$ & $325(92,86)$ & 1 \\
\hline & $<1$ & & $10(5,71)$ & $17(4,86)$ & 0,4875 \\
\hline & {$[1500$} & & $8(4,57)$ & $13(3,71)$ & 0,4552 \\
\hline & {$[2000$} & & $23(13,14)$ & $39(11,14)$ & 0,4854 \\
\hline Fetal hirth weiaht (a) & {$[2500$} & & $57(32,57)$ & $125(35,71)$ & 0,2377 \\
\hline retal Dirtir viergiti (y) & {$[3000$} & & $56(32)$ & $122(34,86)$ & 0,2442 \\
\hline & {$[3500$} & & $18(10,30)$ & $31(8,86)$ & 1 \\
\hline & {$[4000$} & & $2(1,14)$ & $2(0,57)$ & 0,4876 \\
\hline & $\geq 4$ & & $1(0,57)$ & $1(0,29)$ & 0,6109 \\
\hline
\end{tabular}

Table 2: Relationship between obstetrical parameters, maternal age and parity.

\begin{tabular}{|c|c|c|c|c|}
\hline Obstetricals Parameters & Parity & $\begin{array}{c}\text { Women } \geq \mathbf{4 0} \text { years old } \\
n(\%)\end{array}$ & $\begin{array}{c}\text { Women } 20 \text { to } 35 \text { years old } \\
n(\%)\end{array}$ & $p$ value \\
\hline \multirow{3}{*}{ Emergency caesarean } & Parity 1 & $5(2,86)$ & $23(6,57)$ & 0,0005 \\
\hline & Parities 2 to 3 & $25(14,29)$ & $17(4,86)$ & 1 \\
\hline & Parities $\geq 4$ & $34(19,43)$ & $2(0,57)$ & 0,0002 \\
\hline \multirow{3}{*}{ Episiotomy } & Parity 1 & $4(2,28)$ & $40(11,42)$ & 0,0452 \\
\hline & Parities 2 to 3 & $3(1,71)$ & $4(1,14)$ & 1 \\
\hline & Parities $\geq 4$ & $1(0,57)$ & $1(0,29)$ & 0,7222 \\
\hline \multirow{3}{*}{ In utero fetal death } & Parity 1 & $2(1,14)$ & $6(1,71)$ & 0,5944 \\
\hline & Parities 2 to 3 & $2(1,14)$ & $4(1,14)$ & 1 \\
\hline & Parities $\geq 4$ & $6(3,42)$ & $3(0,86)$ & 0,2307 \\
\hline \multirow{3}{*}{ Instrumental extraction } & Parity 1 & $0(0,00)$ & $3(0,86)$ & 0,4000 \\
\hline & Parities 2 to 3 & $1(0,57)$ & $1(0,29)$ & 1 \\
\hline & Parities $\geq 4$ & $1(0,57)$ & $1(0,29)$ & 0,8333 \\
\hline
\end{tabular}

haemorrhage occurred at almost the same proportion in both groups ( $4.57 \%$ vs. $4.29 \%, p=0.433)$. The risk of preterm labor was statistically increased with maternal age ( $p=0.03$, $R R=2.44,95 \% C I=2.17$ to 5.45 ). No cases were recorded puerperal infection or maternal death in this series.
Fetal complications: For fetal risks (Table 4), maternal age 40 years and older was not associated with a significant risk of fetal complications compared to age 20-35. In fact, the in utero fetal death rate was $5.71 \%$ in the exposed group vs. $3.71 \%$ in the unexposed group ( $p=0.151)$; the birth weight 
Table 3: Maternal complications' risk depending on the age.

\begin{tabular}{|c|c|c|c|c|c|c|}
\hline \multicolumn{2}{|c|}{ Maternal complications } & $\begin{array}{c}\text { Women } \geq \mathbf{4 0} \text { years old } \\
n(\%)\end{array}$ & $\begin{array}{c}\text { Women } 20 \text { to } 35 \text { years old } \\
n(\%)\end{array}$ & $p$ value & $R R$ & IC à $95 \%$ \\
\hline \multicolumn{2}{|c|}{ Hypertension } & $10(5,71)$ & $15(4,29)$ & 0,236 & 1,33 & {$[0,61-2,90]$} \\
\hline \multicolumn{2}{|c|}{ Placenta prævia } & $9(5,14)$ & $11(3,14)$ & 0,137 & 1,63 & {$[0,69-3,87]$} \\
\hline \multicolumn{2}{|c|}{ Gestational diabete } & $1(0,58)$ & $1(0,29)$ & 0,538 & 2,12 & {$[0,13-33,70]$} \\
\hline \multicolumn{2}{|c|}{ Pregnancy pathologies* } & $20(11,43)$ & $27(7,71)$ & 0,084 & 1,48 & {$[0,85-2,56]$} \\
\hline \multicolumn{2}{|c|}{ Threat of abortion } & $1(0,57)$ & $0(0,00)$ & 0,10 & infini & {$[-0,18-0,56]$} \\
\hline \multicolumn{2}{|c|}{ Threat of premature labor } & $11(6,29)$ & $9(2,57)$ & 0,03 & 2,44 & {$[2,17-5,45]$} \\
\hline \multicolumn{2}{|c|}{ Premature rupture of membranes } & $7(4,00)$ & $8(2,28)$ & 0,25 & 1,75 & {$[1,43-4,29]$} \\
\hline \multirow{3}{*}{ Caesarean section } & Emergency & $17(9,71)$ & $76(21,71)$ & & & \\
\hline & Scheduled & $64(36,57)$ & $42(12,00)$ & $10^{-10}$ & 3,04 & {$[2,15-4,30]$} \\
\hline & Total & $81(46,28)$ & $118(31,71)$ & 0,003 & 1,41 & {$[1,12-1,77]$} \\
\hline \multicolumn{2}{|c|}{ Post-partum haemorrhage } & $8(4,57)$ & $15(4,29)$ & 0,433 & 1,06 & {$[0,46-2,46]$} \\
\hline
\end{tabular}

Table 4: Fetal complications'risk depending on maternal's age.

\begin{tabular}{|c|c|c|c|c|c|}
\hline Fetal complications & $\begin{array}{c}\text { Women } \geq 40 \text { years old } \\
n(\%)\end{array}$ & $\begin{array}{c}\text { Women } 20 \text { to } 35 \text { years old } \\
n(\%)\end{array}$ & $p$ value & $\boldsymbol{R} R$ & IC à $95 \%$ \\
\hline In utero fetal death & $10(5,71)$ & $13(3,71)$ & 0,1517 & 1,53 & {$[0,68-3,43]$} \\
\hline Prematurity & $40(22,86)$ & $69(19,71)$ & 0,202 & 1,15 & {$[0,82-1,63]$} \\
\hline Low birth weight $(<2500 \mathrm{~g})$ & $41(23,42)$ & $69(19,71)$ & 0,151 & 1,16 & {$[0,87-1,54]$} \\
\hline Apgar index in the 5 th minute $<7$ & $21(12,00)$ & $35(10,00)$ & 0,242 & 1,20 & {$[0,72-1,99]$} \\
\hline Admission to neonatal resuscitation & $23(13,14)$ & $50(14,30)$ & 0,365 & 0,92 & {$[0,58-1,45]$} \\
\hline Perinatal death* & $13(7,43)$ & $14(4,00)$ & 0,052 & 1,85 & {$[0,89-3,86]$} \\
\hline Macrosomie (Poids > 4000g) & $3(1,71)$ & $3(0,86)$ & 0,065 & 1,56 & {$[0,69-3,51]$} \\
\hline
\end{tabular}

rate below $2500 \mathrm{~g}$ of $23.42 \%$ vs. $19.71 \%$ in the unexposed group ( $p=0.151)$; the fetal macrosomia rate of $1.71 \% v s$. $0.86 \%$ in the unexposed group ( $p=0.065)$; the premature birth rate of $22.86 \% v s .19 .71 \%$ in the younger group ( $p=$ 0.202 ) and the Apgar index rate at birth $<7$ in the $5^{\text {th }}$ minute of $12.0 \%$ in the group exposed vs. $10.0 \%$ in the unexposed group ( $p=0.242)$.

As for admission to neonatal resuscitation, the rate was slightly lower in women aged 40 and over compared to women aged 20 to 35 , but without a significant difference (13.14\% vs. $14.30 \%, p=0.365)$. We recorded $7.43 \%$ perinatal death in women aged 40 and over vs. $4.0 \%$ in younger women ( $p=0.052, R R=1.85,95 \% C I=0.89$ to 3.86). A case of fetal malformation was observed among neonates from older women. It was anencephaly.

\section{Discussion}

\section{Frequency}

The frequency of pregnancy among women aged 40 and over was at most in 2010 and then remained stable in 2011 and 2012 to increase slightly in 2013 in this study. In contrast to the situation in developed countries, late pregnancies have become a concern in Western countries for more than 20 years because of their constant increase and the risks they may pose [4]. A population-based cohort study using data on all single births in 2004-2008 performed in the North Western Perinatal Survey based at the University of Manchester, United Kingdom found a birth rate of $18.18 \%$ in women over 35 and 3.13\% in those over 40 [7]. In 2013, 20\% of births in England and Wales were among those aged 35 and over and $4 \%$ among women aged 40 compared to $6 \%$ and $1 \%$ respectively in 1980 [8]. The proportion of older primipara found in our study was much lower than in these countries. According to the fourth demographic and health study of Madagascar «Enquête Démographique et de Santé Madagascar (EDSMD-IV) » carried out between 2008 and 2012, if we observe the four sources making it possible to trace the fertility trends in Madagascar, we note first of all the precocity of the fertility to 15-19 years of age, regardless of the year of the survey, with an estimated rate of more than 148 births per 1,000 women; and second, a maximum of fertility reaches 20-24 years of age. Moreover, in 20082009 , it was found that fertility declined rapidly after 20 24 years [3]. In addition to the factors already mentioned, the acceleration of the development of medically assisted procreation (MAP) and the free access to this offer could contribute to the delay of fertility in developed countries.

\section{Maternal complications'risk}

During pregnancy: Concerning pathologies during pregnancy and peripartum, some authors have noted that arterial hypertension increases with maternal age $[9,10]$, although it cannot be concluded that only age is responsible for the appearance of this condition pregnancy-induced hypertension. In any case, chronic hypertension is more common in older women [10]. We did not find a significant difference with younger women in our study of hypertensive pathology, either before or during pregnancy. According to the literature, compared with younger women, women 
over 35 are at increased risk of spontaneous abortion, ectopic pregnancy, placenta previa, pre-gestational diabetes, eclampsia and pregnancy-induced hypertension [11].

In addition, the occurrence of pathologies such as the threat of abortion and premature rupture of membranes was not statistically influenced by maternal age in our study. On the other hand, the risk of a threat of preterm birth was multiplied by 2.44 . These pathologies are recognized by several authors as the main obstetric complications in older women $[4,11,12]$.

During delivery: The rate of caesarean section was higher compared to younger women (46.28\%vs. $33.71 \%$ ), the indication of which was in most cases urgently asked in large multiparas. This result is similar to that found in the literature. In the 2007 study by Luke and Brown, caesarean section rates in nulliparas and multiparas were $43 \%$ vs. $28.6 \%$ and $28.3 \%$ vs. $21.1 \%$, respectively [12]. According to Joseph and colleagues in 2005 , the cesarean section rate in nulliparas was $50 \%$ vs. $23 \%$ [1]. Similarly, for Jahromi, in 2008, the caesarean section rate was $58 \%$ vs. $35.5 \%$ with an odds ratio of 2.50, 95\% CI [1.67-3.75] [13]. Elderly primiparous women were less exposed to emergency cesareans and episiotomy compared to multiparas. This result on the episiotomy is contrary to that of the study carried out in Morocco on the risk factors of episiotomy, finding again that primiparity exposed women to episiotomy whereas maternal age did not influence on the realization of this act [14]. In addition to the risk of emergency cesarean section, which is often associated with obstructed labor, mothers' demand for caesarean section is more common among older women. This is often related to the anxiety of the woman but also of the obstetrician [11]. In this case, the caesarean section is programmed for prophylaxis. When women gave birth vaginally, the instrumental extraction rate was low in both groups (two deliveries for each group) did not allow a conclusion to be drawn. According to the literature, the rate of instrumental extractions is higher in women over 40 years, regardless of parity [4].

In post-partum: Maternal mortality remains a major health problem in developing countries. In the literature, the maternal mortality rate increases with age [15-17], who reported even greater maternal mortality risks at the age of 40 , whose respective $R R$ s were 5,7 and 30 . The main causes of mortality implicated in the literature are obstetric hemorrhages, vascular pathologies, infections and cardiomyopathies $[15,18]$. No cases of puerperal infection or maternal mortality were found in our study in patients 40 years of age and older. The postpartum haemorrhage rate was comparable in both groups.

\section{Fetal complications'risk}

Birth weight: The birth weight of newborns from older mothers was slightly lower compared to the younger ones, but the difference was not significant. Luke and Brown found that birth weight decreased with maternal age $[12,19]$. At the extreme, in the literature, a higher rate of macrosomes or newborns weighing more than the $90^{\text {th }}$ percentile is found, but there is no significant difference for more than $4.5 \mathrm{~kg}$, these are more likely to be found in the maternal age group of 35-39 years, or in older multiparas [4].

Prematurity: Despite the difference in rates, $22.86 \%$ vs. $19.71 \%$, the relationship between maternal age and prematurity was not found in our study. However, American data on the relationship between maternal age at first birth and pregnancy outcome by maternal race in the United States showed that there was no significant difference in the occurrence of preterm birth in older women [19].

Neonatal asphyxia and perinatal death: The proportion of neonatal asphyxia and perinatal death was high at $12 \%$ and $7.43 \%$, respectively, in neonates from elderly women. In the literature, perinatal mortality increases with age $[11,20]$. In the United States, this stillbirth was 3.73, 6.41 and 8.65 per 1,000 pregnancies in progress respectively, women under 35,35 to 39 and 40 or over, with the risk of a sudden increase to 40 weeks' gestation [11].

The occurrence of fetal death is partly secondary to agerelated gamete aging leading to fetal malformations but also to other pathologies related to multiparity such as uterine rupture and peripartum haemorrhage [21]. In our study, a slight difference between the two groups was found in perinatal death but not statistically verified. Only one case of fetal malformation was observed among neonates from older women.

Despite the decline in the age of pregnancy in several countries, the pregnancy rate after 40 years remains low in Madagascar due to the early fertility. Women aged 40 and over are mainly made up of large multiparas. The fate of pregnancy is especially marked by the frequency of prophylactic caesarean section. Age over 40 years does not expose women or their children to particular pathologies.

\section{Acknowledgement}

We would like to thank all the team who participated in the realization of this study and the writing of this article, namely:

- Rakotomalala Zoly Nivoarimelina: drafting of the article, formatting according to the recommendation, translation into English

- Rakotozanany Besaina: study design

- Razafindraibe Andriatompoina Felanarivo: data collection

- Ramarokoto Malalafinaritra Patrick Marco: correction of the English translation 
- Rafamatanantsoa Jean Florent : statistical calculation

- $\quad$ Kapche Wato Edith: redaction in French

- Randriambololona Domoina Malala Aurélia: final correction, coverage

- Andrianampanalinarivo Hery Rakotovao: Director of the Obstetric Gynecology Hospital of Befelatanana (CHUGOB)

Head of Archives at the Obstetric Gynecology Hospital of Befelatanana.

\section{References}

1. Belaisch-allart J, Castaing N, Grefenstette I, Larousserie F, Mayenga $\mathrm{JM}$, et al. Late childhood desire: Maternal-fetal risks. In: Lansac J. Pregnancy and childbirth after 40 years. Update extract in Medical Gynecology. CNGOF. 2008; 73-91.

2. Schummers L, Hacker MR, Williams PL, Hutcheon JA, Vanderweele $\mathrm{TJ}$, et al. Variation in relationships between maternal age at first birth and pregnancy outcomes by maternal race: a population-based cohort study in the United States. BMJ Open. 2019; 9: e033697. PubMed: https://www.ncbi.nlm.nih.gov/pubmed/31843851

3. National Institute of Statistics. Fourth demographic and health study of Madagascar. Enquête Démographique et de Santé Madagascar (EDSMD-IV). Preliminary report. INSTAT / DDSS / October 2009.

4. Martin A, Maillet R. Pregnancies after 40 years. In Lansac J. Update excerpt in Gynecology and Obstetrics. CNGOF. 2005; 29: 65-92.

5. Beydoun $\mathrm{H}$, Itani $\mathrm{M}$, Tamim $\mathrm{H}$, Aaraj $\mathrm{A}$, Khoolgali $\mathrm{M}$, et al. Impact of maternal age on preterm delivery and low birthweight: a hospitalbased collaborative study of nulliparous Lebanese women in Greater Beirut. J Perinat. 2004; 24: 228-235.

PubMed: https://www.ncbi.nlm.nih.gov/pubmed/15029216

6. National Institute of Statistics. Third demographic and health study of Madagascar «Enquête Démographique et de Santé Madagascar (EDSMD-III) ». Preliminary results. INSTAT / DDSS / July 2004.

7. Lean SC, Derricott $H$, Jones RL, Heazell AEP. Advanced maternal age and adverse pregnancy outcomes: A systematic review and metaanalysis. PLoS One. 2017; 12: e0186287.

PubMed: https://www.ncbi.nlm.nih.gov/pubmed/29040334

8. Kenny LC, Lavender T, McNamee R, O'Neill SM, Mills T, et al. Advanced Maternal Age and Adverse Pregnancy Outcome: Evidence from a Large Contemporary Cohort. PLoS One. 2013; 8: e56583.

PubMed: https://www.ncbi.nlm.nih.gov/pubmed/23437176

9. Lampinen $\mathrm{R}$, Vehviläinen-Julkunen $\mathrm{K}$, Kankkunen $\mathrm{P}$. A review of pregnancy in Women over 35 years of age. Open Nurs J. 2009; 6: 33-38. PubMed: https://www.ncbi.nlm.nih.gov/pubmed/19707520
10. Vincent-Rohfritsch A, Leray C, Anselem O, Cabrol D, Goffine F. Pregnancy in women aged 43 years or older: maternal and perinatal risks. J Gynécol Obstet Biol Reprod. 2012; 41: 468-475. PubMed: https://www.ncbi.nlm.nih.gov/pubmed/22622192

11. Johnson JA, Tough S. Report de la Grossesse. J Obstet Gynaecol Can. 2012; 34: S1-S17.

PubMed: https://www.ncbi.nlm.nih.gov/pubmed/28063528

12. Luke B, Brown M. Elevated risks of pregnancy complications and adverse outcome with increasing maternal age. Hum Reprod. 2007; 22: 1264-1272.

PubMed: https://www.ncbi.nlm.nih.gov/pubmed/17289684

13. Jahromi BN, Hussein Z. Pregnancy outcome at maternal age 40 and older. J Obstet Gynecol. 2008; 47: 318-321.

PubMed: https://www.ncbi.nlm.nih.gov/pubmed/11327090

14. Mohamed ELB, Younes A, Abderrazzak K, Nabil AO, Amine A. Facteurs de risques associés à la pratique d'épisiotomie et la survenue des déchirures périnéales chez les mères au niveau de la maternité de I'hôpital Chérif Idrissi dans la région du Gharb Chrarda Bni Hssen (Maroc). Int J Innov Appl Stud. 2014; 7: 911-919.

15. Saucedo M, Deneux-Tharaux C, Bouvier-Colle M-H. Épidémiologie de la mortalité maternelle en France. 2007-2009. 2013; 613-627

16. Bouvier-Colle H. Épidémiologie de la mortalité maternelle en France, fréquence et caractéristiques. Elsevier Masson. 2007; 358-365.

17. Belaisch-Allart J. Grossesse et accouchement après 40 ans. EMC Obstet. 2017; 5-016-B-10.

18. Bauserman M, Lokangaka A, Thorsten V, Tshefu A, Goudar SS, et al. Reprod Health. 2015; 12: S5.

19. Schummers L, Hacker MR, Williams PL, Hutcheon JA, Vanderweele $\mathrm{TJ}$, et al. Variation in relationships between maternal age at first birth and pregnancy outcomes by maternal race: a population-based cohort study in the United States. BMJ Open. 2019; 9: e033697. PubMed: https://www.ncbi.nlm.nih.gov/pubmed/31843851

20. Mamelle N, Venditelli O, Riviere $\mathrm{O}$, Crenn-Hebert C, Lemery D, et al. Perinatal health in 2002-2003 - Observatory of medical practices results of the Sentinel Network. Gynecol Obstet Fertil. 2004; 32: 4-22. PubMed: https://www.ncbi.nlm.nih.gov/pubmed/15597666

21. Bahtiyar MO, Funai EF, Rosenberg $V$, Norwitz E, Lipkind $H$, et al. Stillbirth at term in women of advanced maternal age in the United States: when could the antenatal testing be initiated? Am J Perinatol. 2008; 25: 301-304.

PubMed: https://www.ncbi.nlm.nih.gov/pubmed/18437644

22. Andriamandimbison Z, Randriambololona DMA, Rasoanandrianina BS, Hery RA. Causes of in utero fetal deaths: 225 cases at Befelatanana Hospital, Madagascar. Med Sante Trop. 2013; 34: 78-82. PubMed: https://www.ncbi.nlm.nih.gov/pubmed/23692740. 